\title{
Chartres, le Bois des Poteries
}

$\mathrm{n}^{\circ} 064584$

\section{Olivier Ranger}

\section{(2) OpenEdition}

Journals

Édition électronique

URL : http://journals.openedition.org/adlfi/13977

ISSN : 2114-0502

Éditeur

Ministère de la culture

\section{Référence électronique}

Olivier Ranger, «Chartres, le Bois des Poteries», ADLFI. Archéologie de la France - Informations [En ligne], Centre, mis en ligne le 23 janvier 2015, consulté le 03 mai 2019. URL : http:// journals.openedition.org/adlfi/13977

Ce document a été généré automatiquement le 3 mai 2019.

(c) Ministère de la Culture et de la Communication, CNRS 


\section{Chartres, le Bois des Poteries}

$\mathrm{n}^{\circ} 064584$

\section{Olivier Ranger}

Lien Atlas (MCC) :

http://atlas.patrimoines.culture.fr/atlas/trunk/index.php?

ap_theme=DOM_2.01.02\&ap_bbox=1.460;48.427;1.550;48.469

1 L'emprise de l'évaluation se trouve à l'est du territoire de la commune de Chartres (Eureet-Loir) au lieu-dit du Bois des Poteries. Cette opération précède l'aménagement sur une surface de 10,6 ha, par le District de Chartres, d'un bassin de rétention des eaux pluviales de la future ZAC du Jardin d'Entreprises. La surface sondée représente environ 6,5\% de la surface de ces parcelles. Les vestiges archéologiques se rencontrent essentiellement dans la partie nord-ouest de l'emprise.

2 Une formation résiduelle à silex constituée de silex anguleux, entiers ou fragmentés, emballés dans une matrice argileuse se rencontre, à des profondeurs variables, sur l'ensemble de l'emprise. Elle affleure notamment dans toute la moitié sud-est de l'emprise. Sur le restant de l'emprise se trouvent des argiles plastiques de teintes très variables (grise, blanche, lie-de-vin) associées localement à des grès ladères ferrugineux.

Dans le sondage 24, deux concentrations d'artefacts siliceux sont apparues à $50 \mathrm{~cm}$ sous la surface actuelle dans une couche d'une puissance de 0,10 m composée de limon argileux marron clair contenant des nodules de manganèse. Seule la concentration localisée au sud du sondage a pu faire l'objet d'une fouille planimétrique qui a livré 103 artefacts concentrés sur environ $4,5 \mathrm{~m}^{2}$ et sur une épaisseur de quelques centimètres. Le mobilier lithique est composé de 7 blocs testés, 14 nucléus dont 6 sont à débitage laminaire, 61 éclats, 13 cassons et 8 outils. L'ensemble du mobilier est relativement frais et légèrement patiné. La matière première est un silex à grain fin issu de blocs branchus à cortex peu épais. Le caractère homogène de l'ensemble est validé par la faible étendue de l'amas mais aussi par 9 remontages. La composition de cet ensemble montre que la matière première utilisée (donc choisie) n'est pas de la meilleure qualité. Cependant, tous 
les produits et sous-produits issus tant des débitages d'éclats que laminaires ont été soustraits. Trop d'éléments (tant qualitatifs que quantitatifs) manquent pour pouvoir décrire les chaînes opératoires et proposer une datation fiable de cet ensemble.

4 Une fosse oblongue est apparue à $0,70 \mathrm{~m}$ de profondeur dans une couche de limon argileux marron clair. D'une largeur de 2,20 m, elle atteint une profondeur de $1,50 \mathrm{~m}$ sous la surface actuelle. Le profil est une cuvette irrégulière. 1225 tessons, soit 4,5 $\mathrm{kg}$ de céramique non tournée, appartenant à un vase à fond plat à pâte grossière sont issus de cette fosse. Le bord présente une lèvre aplatie et épaissie par le rajout d'un cordon lisse à l'extérieur du vase. Un second cordon décoré à la baguette a été appliqué $5 \mathrm{~cm}$ sous le bord. Il est relié au premier par des cordons verticaux appliqués et également décorés à la baguette. Les vases de stockage ornés de cordons se rencontrent du Bronze ancien au début du second âge du Fer. Cependant, l'organisation du décor du vase du Bois des Poteries, si elle ne trouve pas de comparaison en région Centre pour les périodes concernées, rappelle les jarres dont la partie supérieure est décorée de cordons horizontaux, verticaux et obliques à impressions digitales, caractéristiques de la Culture du Rhône (Bronze ancien). En région Centre, les sites où des ensembles du Bronze ancien sont connus sont rares : le Fort-Harrouard à Sorel-Moussel en Eure-et-Loir, les Dix-Neuf à Saint-Pierre-des-Corps et les Marais à Barrou (Indre-et-Loire).

Deux fosses de foyers circulaires à parois rubéfiées ont été découvertes à $60 \mathrm{~cm}$ sous la surface actuelle. L'observation du comblement de la structure 1 montre deux phases: phase d'utilisation avec un limon argileux charbonneux noir, issu des résidus d'une combustion incomplète de matières végétales; puis, limon argileux gris parsemé de charbons de bois correspondant à l'abandon de la structure et donc à la dégradation des parois et à un apport de sédiment par ruissellement. L'attribution chronologique de ces deux structures reste difficile en l'absence de mobilier archéologique. Des charbons de bois présents dans le comblement de l'une des structures ont été prélevés en vue d'une datation par ${ }^{14} \mathrm{C}$.

La période gallo-romaine est représentée par un réseau parcellaire peu dense. Les tronçons de fossés reconnus dans les sondages 40 (St. 8), 34 (St. 9) et 25 (St. 11) appartiennent probablement à un même fossé traversant l'emprise d'est en ouest. Ils montrent un profil en cuvette. La largeur est de $0,60 \mathrm{~m}$ pour une profondeur de $0,70 \mathrm{~m}$ sous la surface actuelle. Le remplissage se compose d'un limon marron-gris compact peu différent de l'encaissant. Bien qu'étant d'orientation nord-sud il est difficile d'affirmer que les tronçons de fossés reconnus dans les sondages 16 (St. 6) et 38 (St. 3) appartiennent à un même fossé. Leur profil est en cuvette. La largeur des deux structures est de $0,50 \mathrm{~m}$ pour une profondeur de $1,10 \mathrm{~m}$ sous la surface actuelle pour le fossé 3 et $0,90 \mathrm{~m}$ pour le fossé 6. Le remplissage se compose d'un limon marron-gris compact. La découverte dans le tronçon de fossé 8 du sondage 40 d'une cruche mono-ansée attribuable au II $\mathrm{e}$. apr. J.-C. placerait donc ce réseau au début de notre ère. 
INDEX

Index chronologique : Protohistoire, Gallo-romain

Mots-clés : silex, céramique, foyer

operation Évaluation archéologique (EV)

Index géographique : Centre, Eure-et-Loir (28), Chartres 